\title{
Aspects that Debilitate the Quality of Braille among Learners with Visual Impairment in Kgatleng District in Botswana
}

\author{
Joseph Habulezi \\ University of Botswana \\ Gaborone, Botswana
}

\begin{abstract}
This qualitative study investigated the aspects that debilitate the quality of braille among learners with visual impairment at an institution in Kgatleng District in Botswana. The study was conducted over a two-month period at a school that caters for learners with total blindness. The participants, who included five special education trained teachers and nine learners with visual impairment, were purposively selected. The study utilised interviews and document analysis to collect data. Thematic and content data analyses were done as data from the two data collection methods was integrated. The results of the study indicate that the special education specialist teachers are underutilised in their area of specialty. In addition, the larger school community views it a waste of human resource for specialist special education teachers to instruct learners in braille. Consequently, there is no deliberate program to teach braille to learners with visual impairment especially that both learners and special education teachers have very tight schedules emanating from a packed curriculum and high teaching loads. The onset of the visual impairment also has a significant influence on the rate of learning braille and the development of the sense of touch. The study recommends, among others, a paradigm shift in the inclusive education practices at the school to improve the quality of braille and academic performance of learners with visual impairment.
\end{abstract}

Keywords: Visual Impairment; Quality of Braille; Aspects; Botswana.

\section{Introduction}

The consistently increasing number of learners with visual impairment using amanuenses when writing final examinations at a senior secondary school in Botswana accentuates debilitation in the quality of Braille among the learners. The Special Education Department (2016) reports that some learners with visual impairment have been experiencing difficulties communicating in braille. As a consequence, school management, with the help of the regional education office, has been hiring personnel to read out assessment items to the learners and record responses. The practice is aimed at fulfilling one of Botswana's vision 
2036 guidelines on the promotion of equal educational opportunities and academic competencies (education with production) for all Batswana leaving no one behind because education and skills are the basis for human resource development (Government of Botswana, 2016).

Braille is a tactile system of raised dots that can be read with the fingers. Tobin and Hill (2015) state that the basic element of Braille is the 'cell', made up of an array of two columns and three rows. Each character represents a combination of one to six raised dots which may be raised at one of the six positions to form 64 possible subsets (Pring, 1994; Radojichikj, 2015). People with visual impairment mostly use the system. Braille is used worldwide because it is one of the keys to literacy for people who are blind (World Blind Union, 2015). It is used more so that it includes users on all levels and permits the users to take part in many life skills. So far, (Njue, Aura \& Komen, 2014), Braille is still the principal means of reading and writing for people with visual impairment world over. There is, however, notable decline in its usage in developing countries like Britain, German, United States of America, Spain, France and Canada; including South Africa, due to technological advancements. In most of these countries, Braille is increasingly being used in functional reading and teachers at numerous schools for persons with blindness report a change in the needs and user trends of braille readers (Alden, 2015; Radojichikj, 2015). To the contrary, Braille is widely used as a mode of communication in Botswana and it is for this reason that the quality of Braille has been of concern to policy implementers (Special Education Department, 2015).

Learners with visual impairment do not learn Braille automatically but it is a skill that they need to acquire. Owing to Braille's being a complex system with many rules that learners need to master, most learners face difficulties in learning how to use it. The difficulty with braille, (Hoffman, 2010; Makondo, 2015), emanates from the fact that Braille is time consuming, bulky, strenuous, slows reading and needs continuous practice. Often times, there is poor braille production in aspects that include the braille code, format, quality of embossing, binding, labelling and packaging of the product being supplied to end users (Schnackenberg, 2016).

Despite the highlighted glitches, braille is a friendlier system if learnt and used consistently. Persons who have learnt braille from an early age, taught by dedicated competent teachers, with a sound knowledge of the braille code have become successful braille users who find braille enjoyable and convenient as compared to other forms of simulated braille (Emerson, Holbrook, \& D'Andrea, 2009). These individuals have gone on to master skills relating to the use of assistive technology such as braille devices, adapted computers and smart phones. From research, the findings show that competent braille users have used braille for a considerable period of time or were taught pre braille skills at a tender age (Fish-Hodgson \& Khumalo, 2015; Alden, 2016). But where there are no competent teachers of braille, learners tend to struggle with the code.

In Botswana, the Government adopted Unified English Braille, a code developed by the International Council on English Braille (ICEB) to bring together several existing braille codes into one unified code for the English-speaking world 
(American Foundation for the Blind, 2017). The Government of Botswana conducted workshops for special education teachers, braillists, learning support workers and the school management team (Department of Special Support Services, 2013). The implementation effectively started in August 2013 although the braille production unit started converting teaching and learning materials in the new code much earlier. The principal aims of implementing UEB in Botswana was for the country to respond to the agreement of the English speaking world in introducing the new code to all learners with visual impairments in schools. Secondly, Botswana wanted to be abreast with the system and the rest of the world. Further, embarking on the implementation of the new code was meant to reduce the ambiguity of braille in languages such as Setswana.

Government of Botswana (2011) believes that special needs of learners with visual impairment are worsened by not being fluent in the language of instruction and that is why the performance of learners has been deteriorating. Muuma (2015) echoes similar submissions in his attribution of the poor academic performance of learners to the low quality of braille among learners. Braille problems lead learners to delay in graduating, be given time off to go and learn braille, bring in the dependence syndrome as scribes have to assist the learners with writing and reading of teaching and learning materials (Webster, 2016). The consequential effect is cost ineptitude. Between 2009 and 2015, some learners at the only senior secondary school that caters for learners who are blind in Botswana had to lose an academic year to learn braille by either deferring their admission to the school or withdrawing from the school for some period (Special Education Department, 2015). After instruction in braille, negligible improvement in some learner's knowledge of braille is observed. The authorities arrange for scribes for a good number of learners to benefit from the educational programmes especially for those who lose sight or whose sight deteriorates when they are about to complete their secondary education.

Table 1: Number of learners with visual impairment amanuensed

\begin{tabular}{ccc}
\hline Year & No of F5 braille users & No of F5 braille users amanuensed \\
\hline 2010 & 7 & 2 \\
2011 & 6 & 3 \\
2012 & 5 & 2 \\
2013 & 6 & 3 \\
2014 & 8 & 2 \\
2015 & 10 & 4 \\
\hline
\end{tabular}

Source: Special Education Department, 2015

The aim of this study was, therefore, to investigate the aspects that debilitate the quality of Braille among learners with visual impairment at an institution in Kgatleng District in Botswana. It was further set to establish the programmes put in place to improve the learners' braille skills. 


\section{Research questions}

The questions that guided the study were:

a) What are the aspects that debilitate the quality of braille among learners with visual impairment at the school?

b) What programs are in place to address the debilitating quality of braille among learners with visual impairment?

\section{Methodology}

This research embraced the interpretivist paradigm because it is based on, among others, the principle of multiple interpretations and generally focuses on meaning and may employ multiple methods of data collection like interviews and observations in order to reflect different aspects of the issue (Collins, 2010; Yin, 2014; Creswell, 2015). Further, a qualitative research approach was adopted because of its ability in providing details about human behaviour, emotion and personality characteristics. It may also include data on participant behaviours, needs, cravings, habits and a variety of other materials that are important in designing a product that will actually fit into a user's life (Madrigal \& McClain, 2012).

The study population comprised the staff and learners of a secondary school with a special education unit mainly for learners with visual impairment. The sample, which was purposively sampled, involved nine learners who use braille and five specialist teachers for learners who are print challenged. The age range of the sample was between 17 and 21for leaners and 35 to 45 years for teachers. $64 \%$ (nine participants) of the participants were females and $36 \%$ (five participants) males

Permission to conduct the research was obtained from the authorities including the resolution of other ethical issues with participants. Data were then collected with the help of unstructured interview guides and analyses of documents. Two interview guides were specifically designed for learners and teachers. Participants were interviewed and with their permission, all interviews were recorded. In addition, documents were analysed.

The documents analysed include:

Table 2: Documents analysed

\begin{tabular}{ll}
\hline Type of document & Reason for analysis \\
\hline Special education reports and minutes & Scrutinise issues dwelt and deliberated on \\
Schemes and records of work & Check on aspects planned and work covered/taught \\
Learners' assessment reports & Recommended programmes for each learner \\
Braille scripts & Quality of braille and transcription \\
Individualised education programmes & What was planned and done for each learner \\
Learner profiles & Know the history of the learners \\
\hline
\end{tabular}

Thematic and content data analyses were employed by identifying logical clusters from the respondents' verbatim responses and documents analysed. 


\section{Findings and discussion}

The study results revealed a wide range of aspects that contribute to the declining quality of braille among braille users. Firstly, Botswana has implemented the 2011 Inclusive Education policy which was launched in 2013 in its quest to attain one of its long term pillars of being an educated and informed nation (Government of Botswana, 1997, 2016). The policy outlines wellarticulated guidelines and commitments on the provision of inclusive educational services country wide for the benefit of all Batswana. Mammoth strides and positive efforts characterise the daily operations of learning support workers. Both human and material resources are abounding. The inclusive education practices, however, are not as understood as one would expect considering the wide coverage, attention and resources directed towards learners with visual impairment.

Documents analysed indicate that the Teaching Service Management deploys teachers to the school on the understanding that they will serve learners with vision challenges because they are trained special education teachers. The Government of Botswana (2006) further guides that teaching loads of teachers with special education qualifications should be reduced to allow them time to support other teachers and learners with visual impairments. To the contrary, most of the special education teachers are over whelmed by high teaching loads because most of the school community views it a waste of human resources to reduce the teaching loads of special education teachers. Like teachers, (as observed by Habulezi et al, 2017), learners with visual impairments also take a minimum of eight subjects which keep them very busy most of the school day that they have very little time for learning braille among others. Noteworthy is the recent deployment of a special needs teacher in the department of special education to improve on special education service provision to learners with visual impairment.

From the interviews conducted, negative attitude towards braille instruction and use emerged as teachers did not want to commit themselves to teaching braille to learners. Of the five teachers interviewed, two of the teachers confessed that they were not confident enough to teach the code. The few learning support workers who were keen to work with the learners lacked appropriate teaching and learning pedagogical skills on braille instruction as they had received no training on the same. Connotatively, this pointed to the shortage of teachers or staff knowledgeable about the braille code which presents a further knock to the learners' improvement of braille standards because teachers are not only unavailable but do not know the braille code very well. Special education teachers showed an impression that all learners were competent in braille and there was no need to instruct anyone in braille at either Form 4 or Form 5 levels. Three out of the five special education teachers interviewed revealed that, while Batswana are generally caring and compassionate, there is negative attitude among some school community members towards special educational issues if their participation increases their work load. In addition, one learner retorted; 
There is some attitude to suggest that braille is not a subject and because of that, it is not taught at all. It is like someone is just helping you as a by the way or doing you a favour.

Another learner shared his experience:

When I was placed at this school, I was told to go to the Central Resource Centre for Special Education to learn braille. There, I was told they are too busy. They then referred me to Pudulogong Rehabilitation and Development Trust for the Blind. Pudulogong is an independent institution that rehabilitates people with visual impairment and they have their own programmes of which braille is just an entity. I took a year there with little success because the institution has its own priorities.

The results are synonymous with Mukhopadyay's (2012) and Dupoux, Hammond, Ingalls and Wolman's (2006) findings that there are pervasive attitudinal barriers in the institutions which restrict success and participation of learners with visual impairment in education. Some learner profiles and assessment reports indicated certain learners used braille at their former schools but changed to large print upon changing schools. Learners themselves also detest the use of braille and would rather use large print if they have some residual vision and only resort to braille when their sight is inept. The occurrence was attributed to missing transition arrangements among the schools. Dimigen, Roy, Horn and Swan (2001) and Kentucky Department of Education (2015) are of the view that a well-managed transition encourages strong feelings of independence, confidence, success and fulfilled accomplishments in special educational programmes like it was the case with Susan, a successful learner illustrated in Dimigen et al's case study.

Records perused all pointed to the missing or delay in assessing the learners for special education provision. Late identification and delay in assessment consequently result in missed early braille intervention opportunities for learners. This coincided with the onset of visual impairment; three of the learners who lost sight at the ages of 9,12 and 16 respectively had problems learning braille with the oldest having the most difficulty. Mike claimed that he had problems in learning braille because he just lost sight in the previous two years and was still working on his sense of touch to improve his tactual acuity. Results show the absence of braille instruction or provision of exercises for developing fine motor skills of hand in order to learn braille. On the other hand, two learners with congenital blindness are competent in braille as they claim they were taught braille right from standard one. The statement conforms with the views and findings of the previous studies, (Fish-Hodgson \& Khumalo, 2015), that persons who have learnt braille from an early age, taught by dedicated competent teachers, with a sound knowledge of the braille code have become successful braille users.

The introduction of unified English braille codes emerged as one of the aspects that is affecting the learners' braille competence. The learners have been using standard British Braille but the Central Resource Centre for Special Education 
has been availing books Brailled in UEB which the learners are not familiar with. Although the changes are negligible, five of the nine learners involved in the study were concerned that the braille in the few books in the department had slight differences that were not brought to their attention. The Department of Special Support Services, in the Ministry of Basic Education, undertook to start the implementation of Unified English Braille in August 2013 to Standard 4s who are currently (2018) in Form 2. The learners from Forms 3, 4 and 5 have not been introduced to the code yet.

\section{Conclusion}

In line with the research question that sought to establish the aspects responsible for the decline in the braille competence of braille users at the school, the study yielded quite an array of detrimental facets of braille development in learners in spite of the country's positive efforts to achieve its ambitious aspirations of becoming an informed and educated nation. The school has had an optimum supply of human and material resources in an effort to improve special education service provision. Nevertheless, the wanting understanding of inclusive pedagogical practices among the school community weighs cripplingly on the learners' braille competency. The learners' and teachers' negative attitudes towards continuous braille usage and instruction respectively negate learner braille proficiency especially when compounded by a compact curriculum and massive teaching loads for teachers. The assumption that learners in advanced secondary school levels know braille works against the learners' chances of receiving braille instruction just as much as the absence of a braille instructional programme at the school or country at large. The missing link in the coordination of the raised system of dots is a minus in all the good intentions of the country. The timing of the supply of books brailled in the new braille code has an effect too on the learners' masterly of braille as most learners in secondary schools are not familiar with the recently introduced braille code.

\section{Recommendations}

In view of the preceding antithetical facets, one would advocate for a paradigm shift in inclusive educational practices of the school through unyielding public awareness on the need for equality of opportunities in all facets of life especially in education. The deployment of special needs personnel is a commendable move and unpacking the curriculum for learners and reduction of special education teachers teaching loads would appreciatively be beneficial to the learners' quality of braille. Of importance, too, would be the introduction of a systematically interwoven braille instruction program that is conveniently coordinated. Instituting coordination of the transition of learners with visual impairment among sister schools could help improve the learners' predicament. This could be augmented by provision of counselling to learners to help them understand that their use of braille has positive educational benefits for their future. There is also need to optimally assess learners for special education provision early to promote early braille intervention. 


\section{References}

Alden, P. (2016). Provision of braille reading and learning material in South Africa: A balance between technology and Braille adding value and creating a love of reading. The South African Library for the Blind: Grahamstown. Doi.org/10.5241/6-iceb-05

Alden, P. (2015). Survey: Braille user needs and trends. Unpublished raw data.

American Foundation for the Blind (2017). All about Braille. Available: http://www.visionaware.org/info/everyday-living/essential-skills/readingwriting-and- vision-loss/all-about-braille/1235

Collins, H. (2010). Creative Research: The theory and practice of research for the creative industries. AVA Publications: London

Creswell, W. J. (2015). 30 essential skills for the qualitative researcher. Sage: London Department of Special Support Services (2013). Implementation of Unified English Braille. DSSS: Gaborone.

Dimigen, G., Roy. A. W. N., Horn. J., \& Swan. M. (2001). Integration of visually impaired students into mainstream education. Journal of visual impairment and Blindness, 95 (3) $161-167$.

Dupoux, E., Hammond, H. Ingalls, L., \& Wolman, C. (2006). Teachers' attitudes toward students with disabilities in Haiti. International Journal of Special Education, 21 (3) 43-58, Doi.org/10.1080/10349120500071894

Emerson, R. W., Holbrook, M. C., \& D'Andrea, F. M. (2009). Acquisition of literacy skills by young children who are blind: Results from the ABC Braille Study. Journal of Visual Impairment E Blindness, 103(10), 610-624

Fish-Hodgson, T., \& Khumalo, S. (2015). Left in the dark: Failure to provide access to quality education to blind and partially sighted learners in South Africa, A Section 27 report.

Government of Botswana, (2016). Vision 2036. Achieving prosperity for all. Vision 2036 Presidential Task Team: Gaborone

Government of Botswana (2011). Inclusive education policy. Ministry of Education and Skills Development: Gaborone.

Government of Botswana, (2006). Establishment register for secondary schools: Directorate of Teaching Service Management. Government Printers: Gaborone

Government of Botswana, (1997).Vision 2016 towards prosperity for all. Government Printers: Gaborone.

Habulezi, J., Batsalelwang, K. P. J., \& Malatsi, N. M. (2017). Factors influencing the poor academic performance of learners with vision impairment in Science Subjects in Kgatleng District in Botswana. International Journal of Learning, Teaching and Educational Research, (11)28-44, Doi.org/10.26803/ijlter.16.11.2

Hoffman, M. (2010). Braille illiteracy is a growing problem. Journal Sentinel 2 (2)

Kentucky Department of Education, (2015). Every chid proficient and prepared for success. Parent guide to alternate K-Prep. Department of Education for students with severe cognitive disabilities: Kentucky

Madrigal, D., \& McClain. B. (2012). Strengths and weaknesses of quantitative and qualitative research. Strategic UX: California.

Makondo, C. (2015). Braille and learners with visual impairment. Unpublished manuscript: ZAMISE Mukhopadhyay, S. (2012). Botswana primary school teachers' perception of inclusion of learners with special educational needs. Journal of Research in Special Educational Needs. 14(1) 33-42. Doi:10.1111/j.14713802.2012.01269.

Muuma, L. (2015). Effects of Braille competency on academic performance. Unpublished manuscript: ZOU.

Njue, S. W., Lillie J., Aura, L. J., \& Komen, Z. (2014). Braille competency among learners with visual impairments: Methodology and learner preparedness factors in 
Thika and Meru Counties, Kenya. International Journal of Humanities and Social Science, 4(10)109-116.

Pring, L. (1994). Touch and go: Learning to read Braille. Reading Research Quarterly, 29(1) 67-74. Doi.org/10.2307/747738

Radojichikj, D., D. (2015). Students with visual impairments: Braille reading rate. International Journal of Cognitive Research in Science, Engineering and Education, Vol. 3(1) 1-6

Schnackenberg, M. (2016). Building better Braille: An Accreditation framework for producers using computer translation software. The Braille Authority of New Zealand: Aotearoa Trust (BANZAT)

Special Education Department, (2016). Annual departmental report. Molefi SSS: Mochudi. Special Education Department, (2015). Annual departmental report. Molefi SSS: Mochudi

Tobin, M. J., \& Hill, E., W. (2015). Is literacy for blind people under threat? Does braille have a future? British Journal of Visual Impairment, Vol. 33(3) 239-250. Doi: $10.1177 / 0264619615591866$

Webster, M. (2016). Over protection in special education. CUTS: Lusaka

World Blind Union, (2015). World Braille Day 2015: Press release. Available: www.worldblindunion.org/English/our-work/our-priorities/Pages/right-2read-campaign.aspx

Yin, R. K. (2014). Case study research: Design and methods. Los Angeles, CA: Sage. Doi.org/10.2172/5141598 